\title{
Ten year clinical evaluation of Starr-Edwards 2400 and 1260 aortic valve prostheses
}

\author{
DAVID HACKETT, IOANNIS FESSATIDIS, RALPH SAPSFORD, \\ CELIA OAKLEY
}

From the Departments of Clinical Cardiology and Cardiac Surgery, Royal Postgraduate Medical School, Hammersmith Hospital, London

SUMMARY The long term performance characteristics of the 2400 and 1260 series of Starit. Edwards aortic prostheses were investigated by a follow up study of clinical outcome of $32 \%$ patients discharged from hospital with isolated aortic valve replacement. Follow up lasted for up to 10 years and was based on 1616 patient-years. The 2400 series cloth covered tracked valve wass implanted in 182 patients from 1974 to 1980 and the 1260 series bare strut silastic ball valve was inserted in 145 patients from 1979 to 1983 . Total 10 year mortality and valve related morbidity were low and no cases of mechanical valve failure were recorded. There were no significarid actuarial differences in mortality or valve related morbidity between the 2400 and 1260 valves.

Starr-Edwards models 2400 and 1260 aortic valve prostheses showed excellent durability with out any mechanical failures over a 10 year period. The long term outcome of isolated aortic valve replacement with these models is associated with a low frequency of valve related complication

Many different mechanical and tissue prostheses are now available for aortic valve replacement and although efforts continue to be made to design durable heart valve prostheses that are free from valve related complications the debate continues about the reported advantages of low profile prostheses or biological valves compared with caged ball valves. ${ }^{1}$ The long term structural durability and consistent long term integrity of xenografts have yet to be demonstrated. ${ }^{2}$ Mechanical heart valve prostheses have reasonable records of structural durability but this advantage is compromised by the risk of thromboembolism and the need for indefinite anticoagulation with its inherent risks. ${ }^{34}$ In patients with chronic mitral valve disease, indefinite anticoagulation is frequently necessary whether or not mitral valve operation is undertaken, and mechanical prostheses are usually chosen for mitral valve replacement because they are more durable than xenografts. Patients with isolated aortic valve disease, however, only require indefinite anticoagulation when mechanical prostheses are implanted; in these patients the choice between

Requests for reprints to Dr David Hackett, Department of Cardiology, Royal Postgraduate Medical School, Hammersmith Hospital, Du Cane Road, London W12 0HS.

Accepted for publication 24 November 1986 mechanical and tissue aortic valve prostheses is nof so clear cut.

Starr-Edwards aortic valve prostheses have been implanted clinically since 1960 and the model $120 \mathrm{~A}$ series dating from 1966 has demonstrated a lower frequency of mechanical dysfunction and throm? boembolism than earlier models. Many large series of patients followed up after isolated Starr-Edwards aortic valve replacement have now confirmed these. findings. ${ }^{5-7}$ Since 1973 we have had extensivis experience with the modern series of Starr-Edwards aortic prostheses. The 2400 model cloth covered tracked valve with stellite poppet, which was designed to reduce cloth wear, was introduced in 1972 and was frequently implanted in patients at this hospital until 1980 when it was withdrawn from general use by the manufacturers because it had no apparent advantages over the 1260 prosthesis. The 1260 model bare strut silastic ball valve witi reduced metal on the inflow surface was introduced in 1968, and continues to be used for aortic valve replacement.

This study was undertaken to examine the lon term performance characteristics of models 2400 and 1260 Starr-Edwards aortic valve prostheses and to provide specific data which may be used to coms pare the clinical performance of other mechanicat and tissue prostheses. The aim of this study was 
consider long term clinical follow up and to relate this to the specific prosthesis used.

\section{Patients and methods}

We reviewed the records of all 993 patients who had cardiac valve prostheses inserted at Hammersmith Hospital between January 1974 and December 1983 and identified 689 cases where a Starr-Edwards valve was inserted. Of these there were 352 consecutive patients discharged alive from hospital who had an isolated aortic valve replacement by a StarrEdwards model 2400 or 1260 prosthesis. During this period only four patients (in 1974) had a StarrEdwards aortic valve replacement with a model other than 2400 or 1260; all four had Starr-Edwards model 2320 non-tracked cloth covered strut metallic ball prostheses and have been excluded from analysis.

The decision to insert a Starr-Edwards prosthesis in the aortic position in these patients was based on several factors. The need for indefinite anticoagulation, an adequate size of aortic root, and the attending cardiologists and cardiac surgeons preference for these prostheses were the most important considerations during this period. Those patients with an aortic root of inadequate size to encompass a caged ball (Starr-Edwards) valve usually had a disc valve (Björk-Shiley) implanted. In general, mechanical prostheses were favoured particularly in younger patients because of their more certain durability whereas xenograft bioprostheses were usually only implanted in those aged over 70 years or in those few patients with specific contraindications to indefinite anticoagulation.

Patients with multiple valve replacements were excluded from this study but the total includes patients undergoing combined procedures, such as open mitral valvotomy or aortocoronary bypass grafting. Operative techniques were standardised and from 1974-78 included myocardial protection by systemic hypothermia, aortic cross clamping, and a beating perfused heart at $28^{\circ} \mathrm{C}$. After 1978 systemic hypothermia at $28^{\circ} \mathrm{C}$ and myocardial preservation at $4-10^{\circ} \mathrm{C}$ with the use of St Thomas's cardioplegic solution was used. Interrupted sutures were almost always used to insert the prosthetic valve. All patients were routinely anticoagulated with warfarin immediately after operation and this was continued indefinitely. Anticoagulation was aimed to maintain standardised British corrected prothrombin ratios in the therapeutic range of 2.5-4.0 times control values.

As the aim of this study was to determine long term outcome in relation to the prosthesis implanted, immediate perioperative and early post- operative non-valve related morbidity and mortality were not analysed and follow up was started from the time of hospital discharge. Patient follow up was obtained retrospectively and by physicians in all cases. Sources of this included records from Hammersmith Hospital cardiac follow up clinics, referral hospital clinics, and in some cases family practitioners. At operation sex, age, rhythm, functional class, ${ }^{8}$ pathology and aetiology of aortic valve disease, previous heart valve prostheses, and associated operative procedures were recorded. Follow up evaluation was continued up to December 1983. The following were analysed: (a) death and its cause if known from clinical and/or necropsy evidence; $(b)$ reoperation to replace the Starr-Edwards prosthesis, and its indication; (c) the presence of the following complications at any time postoperatively - thromboembolism including any sudden focal transient or permanent neurological deficit, anticoagulant related haemorrhage requiring active medical management including blood transfusion or hospital admission, prosthetic valve endocarditis as defined by standard criteris, ${ }^{9}$ primary valve failure resulting in mechanical dysfunction (such as valve occlusion or ball variance) including thrombosis in situ, valve related intravascular haemolysis requiring active medical management including hospital admission or detailed outpatient management, and haemodynamically severe paraprosthetic regurgitation requiring admission or detailed outpatient management.

The significance of univariate analysis was tested with the $\chi^{2}$ test. Standard non-parametric actuarial (Kaplan-Meier) and linearised statistical techniques were used to describe survival and the incidence of valve-related complications. ${ }^{1011}$ Actuarial probability estimates were analysed by the Biomedical Data Package Program (BMDP1L) of the University of California and are presented as mean rates plus or minus one SEM. The Wilcoxon rank test was used for statistical comparisons of artuarial curves.

\section{Results}

We followed up 327 patients ( $92.8 \%$ complete) up to December 1983 - a cumulative total of 1616 patientyears. Most of the patients lost to follow up were living overseas and have not been selected out on any specific criteria. One hundred and eighty two $(55.7 \%)$ patients had Starr-Edwards model 2400 inserted during 1974-80 and $145(44.3 \%)$ had a Starr-Edwards model 1260 inserted during 1979-83 (fig 1). Table 1 lists the clinical, operative, and pathophysiological characteristics of the patients. The aortic valve disease was considered to be congenital in $33.9 \%$ of the total with a rheumatic 
358

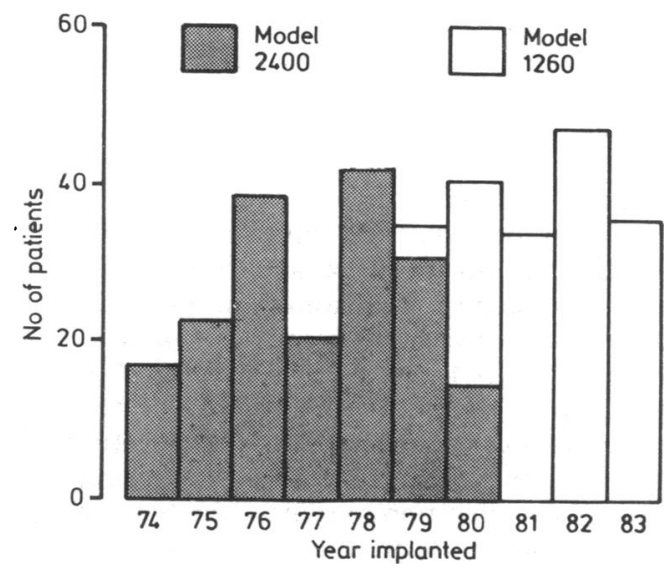

Fig 1 Numbers of patients with isolated Starr-Edwards aortic valve replacement by year and model.

aetiology in only $22.9 \%$. The proportion of patients with congenital aortic valve disease, however, was significantly greater in those undergoing valve replacement with model 2400 prosthesis $(40.7 \%$ vs $25.5 \%, p<0.05)$. At the time of aortic valve

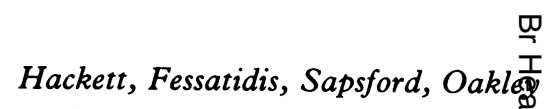
replacement associated procedures were performed in $26.6 \%$ of the patients, most commonly aortocoronary bypass grafting in $14.4 \%$ of the totat. Aortocoronary bypass grafting was performed it significantly more of those patients undergoing valve replacement with model 1260 prothes $(24.1 \%$ vs $6.6 \%, \mathrm{p}<0.001)$. There were no oth significant differences in clinical, pathos physiological, or operative characteristics between those patients with a model 2400 prosthesis and wit model 1260.

During 10 years of follow up 47 patients dies $(2.9 \% /$ patient-year) (table 2$)$. In 38 cases the cause of death could be established from clinical and/क्ष necropsy evidence. In 27 patients this was due to cardiac causes. Most cardiac deaths were associated with the effects of chronic heart failure but in foum cases death could be related to the Starr-Edwards aortic prosthesis, all four being due to thrombo= embolism. Four deaths were indirectly valve related-three resulting from infective endocarditis. which had not be eradicated either medically or by reoperation to replace the Starr-Edwards aortie prosthesis. One anticoagulant related death was due

Table 1 Clinical, pathophysiological, and operative characteristics in patients with Starr-Edwards 2400 and 1260 aortic valve prostheses

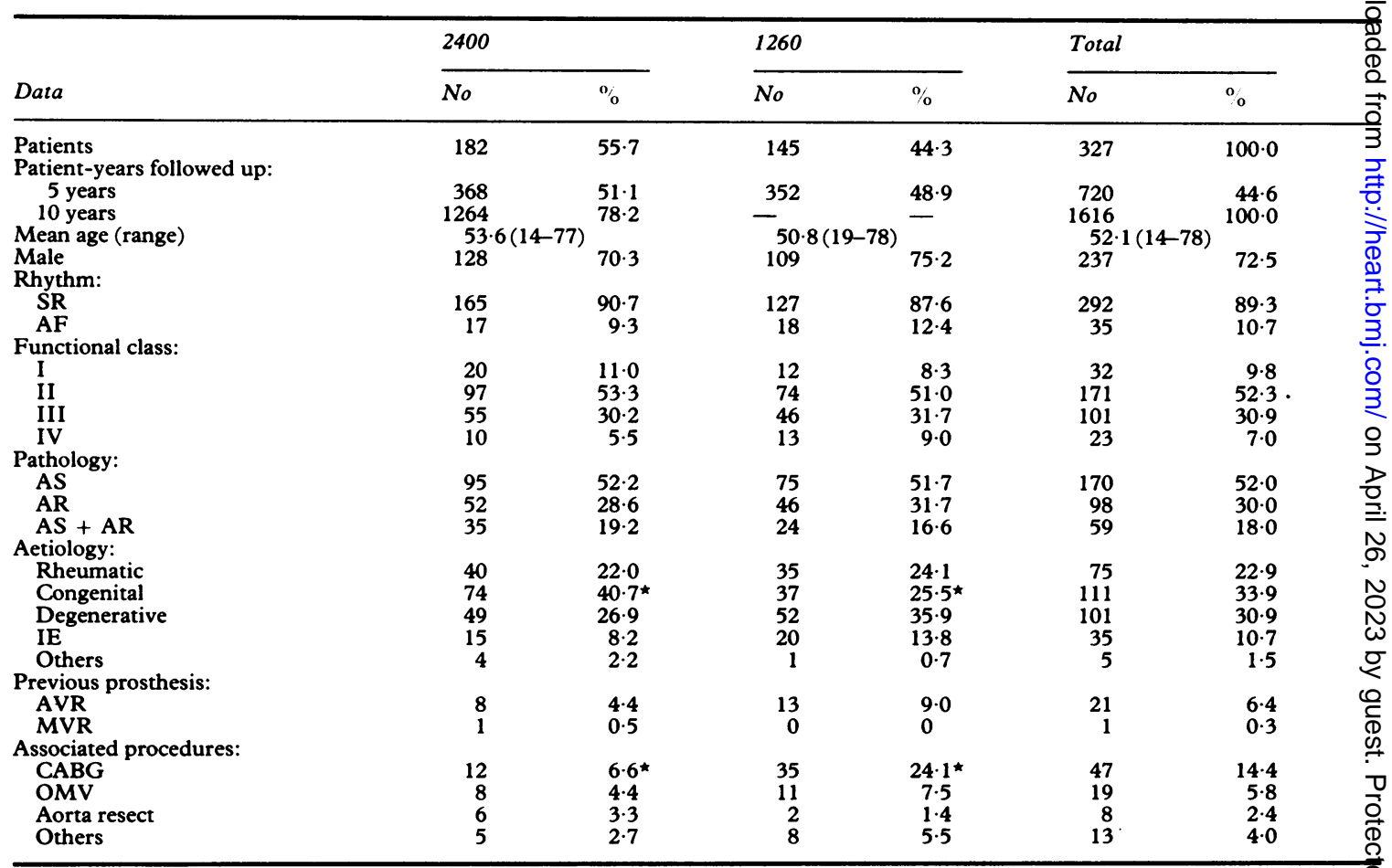

SR, sinus rhythm; AF, atrial fibrillation/flutter; AS, aortic stenosis; AR, aortic regurgitation; AS + AR, aortic stenosis and regurgitatioß IE, infective endocarditis; AVR, aortic valve replacement; $M V R$, mitral valve replacement; CABG, coronary artery bypass grafting; $O M V^{\prime}$ open mitral valvotomy; aorta resect, aortic root replacement.

$\star_{p}<0.05$ for 2400 vs 1260 . 
Table 2 Mortality in patients with Starr-Edwards 2400 and 1260 aortic valve prostheses

\begin{tabular}{|c|c|c|c|c|c|c|}
\hline \multirow[b]{2}{*}{ Data } & \multicolumn{2}{|l|}{2400} & \multicolumn{2}{|l|}{1260} & \multicolumn{2}{|l|}{ Total } \\
\hline & No & $\% / p t-y r$ & No & $\% / p t-y r$ & No & $\% / p t-y r$ \\
\hline \multicolumn{7}{|l|}{ Total mortality: } \\
\hline $\begin{array}{l}\text { At } 5 \text { years } \\
\text { At } 10 \text { years }\end{array}$ & $\begin{array}{l}26 \\
32\end{array}$ & $\begin{array}{l}7 \cdot 07 \\
2 \cdot 53\end{array}$ & 15 & $\underline{4 \cdot 26}$ & $\begin{array}{l}41 \\
47\end{array}$ & $\begin{array}{l}5 \cdot 69 \\
2.91\end{array}$ \\
\hline \multicolumn{7}{|l|}{ Causes: } \\
\hline Cardiac & 18 & 1.42 & 9 & $2 \cdot 56$ & 27 & 1.67 \\
\hline Sudden & 1 & 0.08 & 1 & $0 \cdot 28$ & 2 & $0 \cdot 12$ \\
\hline Valve related & 3 & $0 \cdot 24$ & 1 & $0 \cdot 28$ & 4 & $0 \cdot 25$ \\
\hline Not valve related & 14 & $1 \cdot 11$ & 7 & 1.99 & 21 & $1 \cdot 30$ \\
\hline Not cardiac & 5 & 0.40 & 2 & 0.57 & 7 & 0.43 \\
\hline Not known & 9 & 0.71 & 4 & $1 \cdot 14$ & 13 & 0.80 \\
\hline \multirow{3}{*}{$\begin{array}{l}\text { Actuarial survival (mean }(\text { SEM }))(\%) \text { : } \\
\text { At } 5 \text { years } \\
\text { At } 10 \text { years }\end{array}$} & 32 & $2 \cdot 53$ & 15 & $4 \cdot 26$ & 47 & 2.91 \\
\hline & & & & & & \\
\hline & $\begin{array}{l}83(3)^{\star} \\
72(5)\end{array}$ & & $89(4)^{\star}$ & & $\begin{array}{l}84(2) \\
73(5)\end{array}$ & \\
\hline
\end{tabular}

pt-yr, patient-years. ${ }^{\star} \mathrm{p}=0.15$ for 2400 vs 1260 .
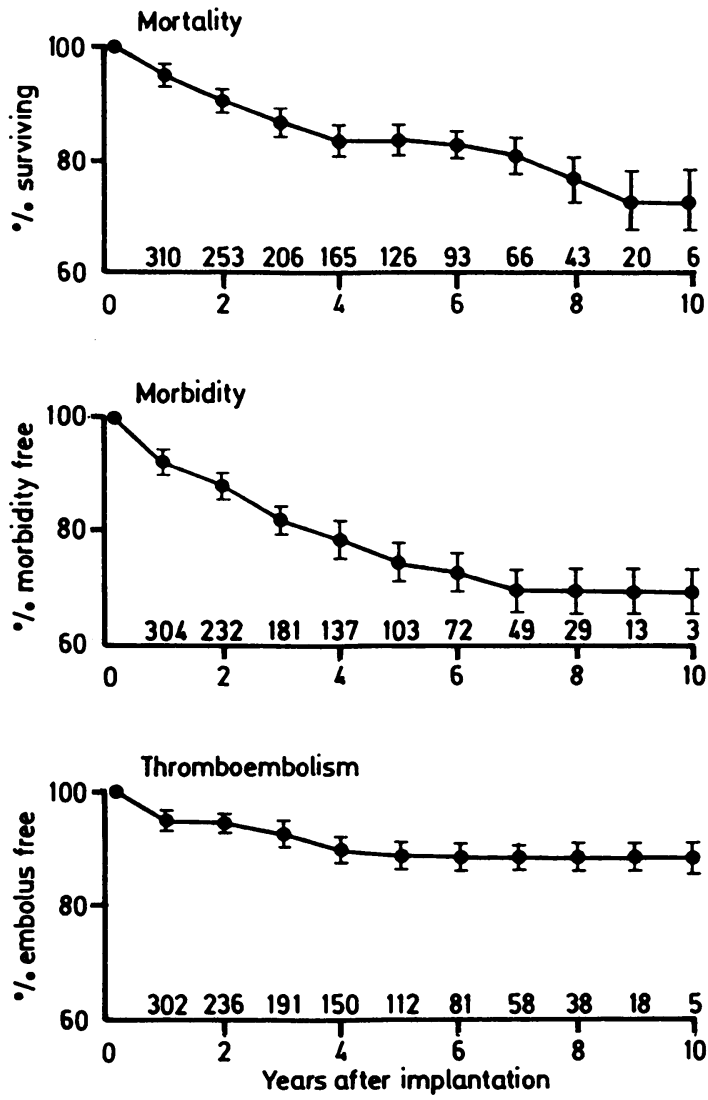

Fig 2 Actuarial estimates of survival, freedom from valve related morbidity, and freedom from thromboembolism for all patients up to 10 years after aortic valve replacement (means (1 SEM)). The total numbers of patients at risk each year are shown above the abscissa. Most valve related complications occurred early after implanatation of the Starr-Edwards aortic valve and no new thromboembolic events were seen after 5 years. to a mid-brain pontine haemorrhage. No deaths could be attributed to paraprosthetic regurgitation or haemolysis and no deaths from primary valve failure caused by mechanical dysfunction or thrombosis in situ were documented. Actuarial estimates of survival were $84(2) \%$ at five years and $73(5) \%$ at 10 years (fig 2),

Table 3 lists the valve related complications that were observed. No cases of primary valve failure caused by mechanical dysfunction or thrombosis in situ were reported. Over 10 years valve related morbidity was documented in 60 patients (3.71\%/patient-year). Thromboembolism, noted in 22 patients $(1.36 \%$ /patient-year), was the most frequent complication. The central nervous system was affected in $18(82 \%)$ cases and in four cases myocardial infarction was assumed to result from thromboembolism to the coronary circulation. Coronary arteriography in three of the latter cases was normal either before or after the event. Ten of the 18 cases of non-fatal thromboembolism to the central nervous system resulted in a severe permanent residual neurological deficit. Transient ischaemic attacks of the central nervous system were recorded in eight patients, all without permanent neurological deficit including four patients who complained of amaurosis fugax. Thromboembolism was not significantly correlated with the presence of atrial fibrillation; the combination occurred in only two patients. Thromboembolic events were observed in a total of 26 patients over 10 years $(1.61 \% /$ patient-year) including the four who died of thromboembolism to the central nervous system (table 4). In all 26 patients these events were observed within five years of the Starr-Edwards aortic valve implantation. Actuarial estimates of freedom from thromboembolic events were $89(2) \%$ at five and also at 10 years (fig 2).

Anticoagulant related haemorrhage was reported in 12 patients $(0.74 \%$ /patient-year $)$, prosthetic valve 
Table 3 Valve related morbidity in patients with Starr-Edwards 2400 and 1260 aortic valve prostheses

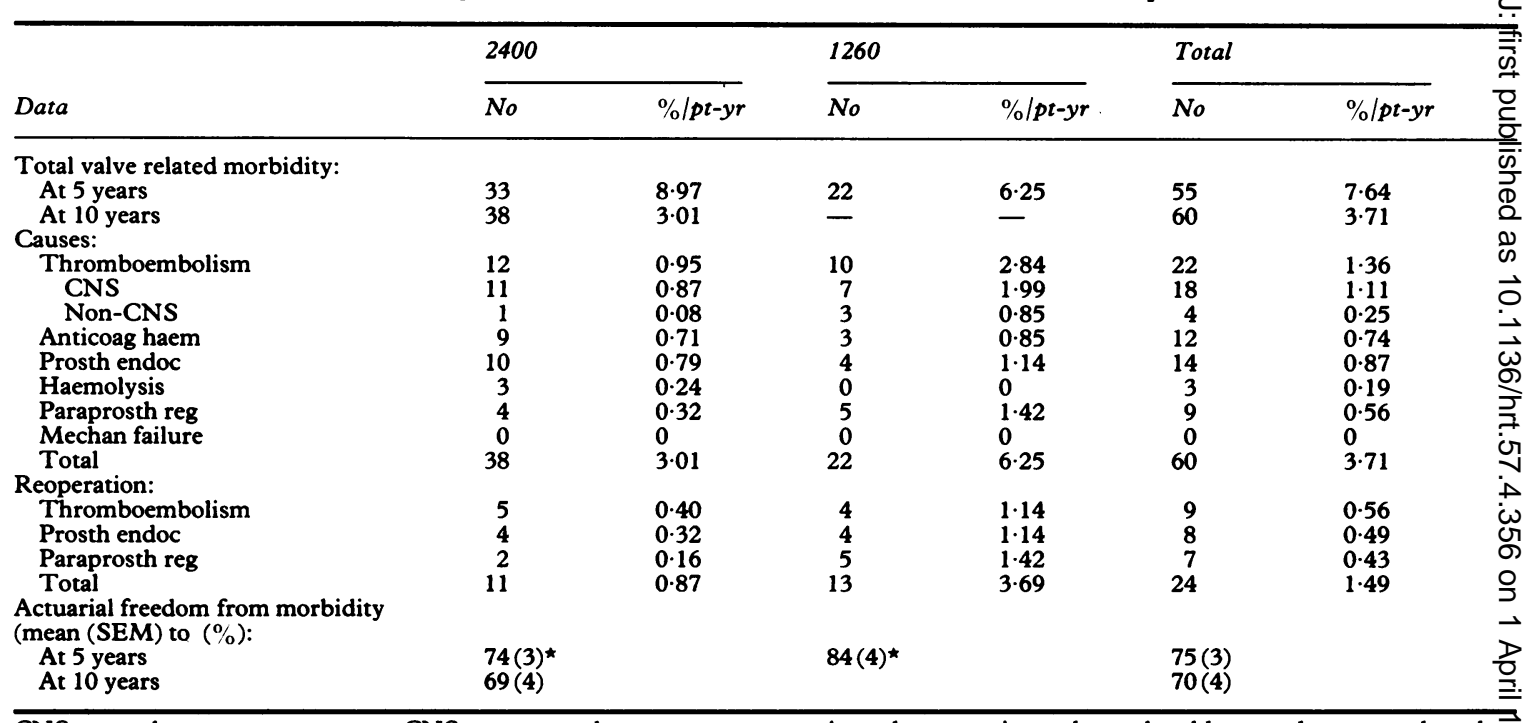

CNS, central nervous system; non-CNS, non-central nervous system; anticoag haem, anticoagulant related haemorrhage; prosth endoç prosthetic endocarditis; paraprosth reg, paraprosthetic regurgitation; mechan failure, mechanical failure; pt-yr, patient-years.

${ }^{\star} p=0.21$ for 2400 vs 1260 .

endocarditis in $14(0.87 \% /$ patient-year $)$, haemolysis in three $(0.19 \% /$ patient-year $)$, and paraprosthetic regurgitation without endocarditis in nine $(0.56 \% /$ patient-year). Actuarial estimates of freedom from all valve related morbidity were $75(3) \%$ at five years and $70(4) \%$ at 10 years (fig 2 ).

Twenty four patients required reoperation ( $1.49 \% /$ patient-year) (table 3$)$. The causes were thromboembolism in nine patients, prosthetic valve endocarditis in eight (with some but haemodynamically not severe paraprosthetic regurgitation in three of these), and severe paraprosthetic regurgitation without infection in seven. In all but one patient (with paraprosthetic regurgitation), reoperation was performed within 12 months of the original aortic valve replacement. Three patients reoperated on for continuing infective endocarditio died at operation or shortly afterwards, and ther was one late death (at one year) after reoperation fo paraprosthetic regurgitation in a patient with Mar@ fan's syndrome.

The incidence of mortality and valve related mor bidity did not appear to be particularly high in any specific year. There were no significant difference 8 evident between the 2400 and 1260 prostheses in the actuarial probability of mortality, valve related mor bidity, or thromboembolic events. A consistent trend towards greater freedom from mortality an valve related complications, however, is apparent for the model 1260 prosthesis over the period 1979-83 compared with the 2400 prosthesis during 1974-78 (fig 3).

Table 4 Total thromboembolic events in patients with Starr-Edwards 2400 and 1260 aortic valve prostheses

\begin{tabular}{|c|c|c|c|c|c|c|}
\hline & \multicolumn{2}{|c|}{2400} & \multicolumn{2}{|c|}{1260} & \multicolumn{2}{|c|}{ Total } \\
\hline & No & $\% / p t-y r$ & No & $\% / p t-y r$ & No & $\% / p t-y r$ \\
\hline $\begin{array}{l}\text { At } 5 \text { years } \\
\text { At } 10 \text { years }\end{array}$ & $\begin{array}{l}12 \\
15\end{array}$ & $\begin{array}{l}\text { tal thrombc } \\
3 \cdot 26 \\
1 \cdot 19\end{array}$ & $\begin{array}{l}\text { lic ev } \\
11\end{array}$ & $3 \cdot 13$ & $\begin{array}{l}23 \\
26\end{array}$ & $\begin{array}{l}3 \cdot 19 \\
1 \cdot 61\end{array}$ \\
\hline $\begin{array}{l}\text { At } 5 \text { years } \\
\text { At } 10 \text { years }\end{array}$ & \multicolumn{4}{|c|}{$\begin{array}{l}\text { Actuarial freedom from thromboembolism (mean (SEM)) (\%) } \\
89(3)^{\star} \\
89(3)\end{array}$} & $\begin{array}{l}89 \\
89\end{array}$ & \\
\hline
\end{tabular}

pt-yr, patient-years. ${ }^{\star} \mathrm{p}=0.61$ for 2400 vs 1260 . 

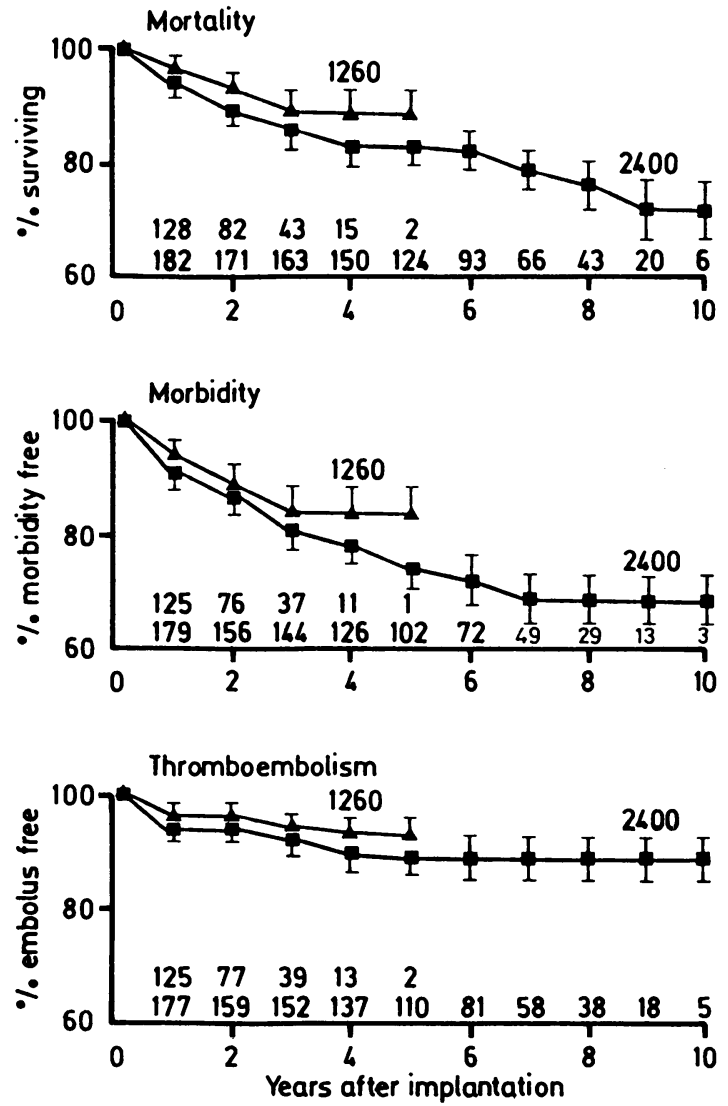

Fig 3 Actuarial estimates of survival, freedom from valve related morbidity, and freedom from thromboembolism for the Starr-Edwards models 2400 and 1260 prostheses up to 10 years after aortic valve replacement (means (1 SEM)). The numbers of patients with each prosthesis at risk each year are shown above the abscissa. The actuarial differences between the 1260 and 2400 prostheses are not statistically significant, but there is a consistent trend towards greater freedom from mortality and valve related complications for the 1260 prosthesis (during 1979-83) compared with the 2400 model (during 1974-78).

\section{Discussion}

This study was performed to define the long term performance characteristics of the modern series of Starr-Edwards aortic valve prostheses and demonstrates that the structural durability of StarrEdwards models 2400 and 1260 aortic prostheses is excellent. There were no reports of cases of mechanical dysfunction from failures such as poppet fracture or embolisation, strut fracture, ball variance, or thrombosis in situ. This accords with other studies of the long term follow up of the modern series of Starr-Edwards aortic prostheses, with no previous reports of strut fractures and negligible frequency of variance of the silastic balls. ${ }^{5-7}$ Thrombosis in situ seems to be very rare in anticoagulated patients with these prostheses. ${ }^{712}$ The late mortality of our patients with Starr-Edwards aortic valve replacement is similar to that reported in other large series and the actuarial survival estimates compare favourably. ${ }^{5-7}$ Although most deaths were from cardiac causes, the Starr-Edwards prosthesis could only be implicated in four $(0.25 \% /$ patient-year $)$ of these due to thromboembolism. When the cause of death was known, this could be indirectly related to the StarrEdwards valve replacement in only six patients (three cases of infective endocarditis, two sudden deaths, and one intracranial haemorrhage). Even if such indirectly related deaths are included, valve related mortality over 10 years still remains low $(0.62 \% /$ patient-year $)$.

Thromboembolism is the most important complication to follow from insertion of mechanical cardiac valve prostheses. ${ }^{3413}$ In this series we recorded a thromboembolic event (according to a comprehensive definition) in 26 patients of which only four were fatal. The frequency of thromboembolism is low compared with other published series. ${ }^{5-7}$ Anticoagulation in these patients was deliberately maintained in the upper part of the therapeutic range (2.5-4.0 times control values) in order to reduce as far as possible the risk of thromboembolism which, if it should occur, may be fatal or result in permanent morbidity. The low frequency of thromboembolism in our series may be attributed in part to the careful anticoagulant control achieved by anticoagulant clinics and to the discipline of the patients. This may be an important factor in determining the choice of valve prosthesis in different countries.

The frequency of anticoagulant related haemorrhage in our series was low. There was one fatal case of pontine haemorrhage but there were no other recorded episodes of intracranial bleeding. Most haemorrhages were gastrointestinal (nine patients), but this was rarely spontaneous and usually a precipitating event could be identified and no serious bleeding complications were observed. Other sites of haemorrhage were intramesenteric and retroperitoneal (one patient each). Anticoagulant problems associated with pregnancy, childbirth, or fetal abnormalities were not included in our analysis but the number of women of childbearing age with Starr-Edwards prostheses in our series was small and anticoagulant problems associated with unrelated (non-cardiac) operations were rare. The low frequency of anticoagulant related haemorrhage in this study favourably compares with that of other published series ${ }^{5-7}$ and again may relate, in part, to careful anticoagulant control.

Prosthetic valve endocarditis developed in 14 
patients; in three cases this was fatal. A wide variety of organisms was responsible, and the variation in the interval between valve replacement and the development of infective endocarditis reflects the usual experience in series of prosthetic valve endocarditis. Six patients required reoperation for endocarditis on eleven occasions, illustrating the surgical difficulty of eradicating the organism when medical treated has failed. ${ }^{914}$ One patient required reoperation on four occasions for endocarditis, but now is well three years after the last operation.

Haemolysis requiring hospital admission or detailed outpatient management was recorded in only three patients. In only one patient was this associated with appreciable paraprosthetic regurgitation. Haemolysis per se was never an indication for reoperation in this series. Appreciable paraprosthetic regurgitation was noted in nine patients of whom seven required reoperation. In two cases paraprosthetic regurgitation appeared after reoperation for prosthetic valve endocarditis, a situation in which the risk of prosthetic dehiscence is high. Reoperation for all but one of the patients (with prosthetic regurgitation) was necessary within the first year after Starr-Edwards aortic valve replacement, confirming that in the absence of endocarditis, paraprosthetic regurgitation probably results from technical factors relating to operation and is not prosthesis related. The frequency for reoperation was low at $1.49 \% /$ patient-year, the indications being almost equally divided among thromboembolism, prosthetic endocarditis, and paraprosthetic regurgitation. Mortality and morbidity after reoperation again probably reflect the underlying aetiology and the patient's condition rather than prosthesis specific events.

In this study there was a consistent, although statistically insignificant, trend towards implantation of the model 1260 being associated with less mortality and fewer valve related complications including thromboembolic events than the 2400 aortic prosthesis. The 1260 prostheses were all implanted during the period 1979-83, however, whereas the 2400 valves were inserted during $1974-80$. Thus our data do not establish whether the trend observed in this study was caused by differences in patient related factors including general improvements in surgery and patient care over these periods of time, or was a genuine but statistically insignificant difference between valve models, or was due to chance. Many patient related factors have been shown significantly to predict a greater probability of developing long term complications. ${ }^{1516}$ Several studies have reported a lower incidence of mortality and thromboembolism for the same prosthesis in patients who had aortic valve replacement performed recently than in comparable patients operated on in earliễ years. $^{517}$ The risk of systemic thromboembolism is high in patients with severe myocardia 1 impairment, ${ }^{18}$ and indeed spontaneous calcifect embolisation can occur in the unoperated patiext with calcific aortic stenosis. ${ }^{19}$ Older age and chron severe aortic regurgitation are associated with a colosiderable reduction in expected longevity. ${ }^{16}$ The ris of developing prosthetic endocarditis is generally independent of the type of prosthesis implanted and the choice of valve for patients with infective endar carditis remains difficult because opinions differ about the risk of recurrence associated with various protheses. $^{142 \theta 21}$

Differences in mortality and valve related mor bidity in our patients compared with other published series are unlikely to be explained by differences patient populations, because our patients resemblegl those in other series in terms of sex, rhythm, func. tional class, aetiology, and pathology; however, outy patients tended to be younger. ${ }^{5-7}$ In one study the Starr-Edwards prostheses were implanted as a valye of second choice in patients with more complicated diagnoses and a high proportion of previous valye surgery which may account for their relatively poor outcome in that study. ${ }^{5}$ Apart from functional clas the severity of preoperative or postoperative valve disease or myocardial function was not considered this study, but we have no reason to suspect significant differences from other series which woun explain differences in mortality or valve related com plications.

Prosthesis related factors that determine mortality and morbidity include reliability, durability, an thromboembolism. No cases of mechanical pros thetic dysfunction were reported in this study, and the frequency of thromboembolism was low. Con? pared with mechanical protheses bioprostheses used for aortic valve replacement show a lower inciden ee of thromboembolism and are not associated with any anticoagulant related haemorrhages; but these advantages are compromised by the increasing need for reoperation because of primary tissue valve fai $\bar{b}$ ure with time. The rate of primary tissue valve faip ure accelerates after six years when the incidence reoperation exceeds that for mechanical aortic pros theses, ${ }^{22}$ and the incidence of primary tissue value failure for bioprostheses is $20-30 \%$ at 10 years 30 There was no statistically significant difference between aortic bioprostheses and the Starr-Edwares 1260 prosthesis in total rates of valve failure at eight years. ${ }^{22}$ Thus for isolated aortic valve replacement there seemed little to choose between mechaniogl and tissue prostheses up to eight years afterward but the Starr-Edwards 1260 valve was more reliabde and durable in the longer term. ${ }^{7}$ 
In summary, the long term structural reliability and durability of the Starr-Edwards models 1260 and 2400 aortic prostheses is excellent. No episodes of mechanical valve failure or thrombosis in situ were observed and actuarial survival estimates of patients with these prostheses compare very favourably with those of other workers. ${ }^{5-7}$ The frequency of thromboembolic events in this study was less than that reported elsewhere, and the frequency of haemorrhagic complications associated with indefinite anticoagulation was also low. Like others, however, we realise that structural durability is only one of many variables to consider when assessing the performance of prostheses. ${ }^{7}$ This series will provide a basis for the comparison of newer valve substitutes, particularly bioprostheses, whose long term structural durability has yet to be established. ${ }^{1213}$

We thank Professor H H Bentall, Professor J F Goodwin, Professor A Maseri, and Mr R de L Stanbridge for allowing us to include their patients in this study. We also thank all those physicians who participated and helped in the follow up of these patients. Statistical advice and help was kindly provided by Mr Vic Aber.

\section{References}

1 Tepley JF, Grunkemeier GL, Sutherland HD'A, Lambert LE, Johnson VA, Starr A. The ultimate prognosis after valve replacement: an assessment at twenty years. Ann Thorac Surg 1981;32:111-7.

2 Oyer PE, Stinson EB, Griepp RB, Shumway NE. Valve replacement with the Starr-Edwards and Hancock prostheses: comparative analysis of late morbidity and mortality. Ann Surg 1977;186:301-9.

3 Edmunds LH. Thromboembolic complications of current cardiac valvular prostheses. Ann Thorac Surg 1982;34:96-106.

4 Fuster V, Pumphrey CW, McGoon MD, Chesebro JH, Pluth JR, McGoon DC. Systemic thromboembolism in mitral and aortic Starr-Edwards prostheses. A 10-19 year follow-up. Circulation 1982;66(suppl I):157-61.

5 Wain WH, Drury PJ, Ross DN. Aortic valve replacement with Starr-Edwards valves over 14 years. Ann Thorac Surg 1982;33:562-9.

6 Starr A, Grunkemeier GL, Lambert LE, Thomas DR, Suginuira S, Lefrak EA. Aortic valve replacement: a ten-year follow-up of non-cloth-covered vs clothcovered caged-ball prostheses. Cardiovasc Surg 1977;56(suppl 2):133-9.

7 Miller DC, Oyer PE, Mitchell RS, et al. Performance characteristics of the Starr-Edwards Model 1260 aortic valve prosthesis beyond ten years. $J$ Thorac Cardiovasc Surg 1984;88:193-207.

8 The criteria committee of the New York Heart Association. Diseases of the heart and blood vessels; nomenclature and criteria for diagnosis. 6th ed. Boston: Little, Brown, 1964.

9 Baumgartner WA, Miller DC, Reitz BA, et al. Surgical treatment of prosthetic valve endocarditis. Ann Thorac Surg 1983;35:87-102.

10 Kaplan EL, Meier P. Non parametric estimations from incomplete observations. J Am Stat Assoc 1958;53: 457-81.

11 Gehan EA. Generalised Wilcoxon test for comparing arbitrary singly-censored samples. Biometrica 1965; 52:203-23.

12 Metzdorff MT, Grunkemeier GL, Pinson CW, Starr A. Thrombosis of mechanical cardiac valves: a qualitative comparison of the silastic ball valve and the tilting disc valve. J Am Coll Cardiol 1984;4:50-3.

13 Bodner E, Wain WH, Haberman S. Assessment and comparison of the performance of cardiac valves. Ann Thorac Surg 1982;34:146-56.

14 Ivert TSA, Dismukes WE, Cobbs CG, Blackstone EH, Kirklin JW, Bergdahl LAL. Prosthetic valve endocarditis. Circulation 1984;69:223-32.

15 MacManus Q, Grunkemeier GL, Lambert LE, Teply JF, Harlan BJ, Starr A. Year of operation as a risk factor in the late results of valve replacement. $J$ Thorac Cardiovasc Surg 1980;80:834-41.

16 Mitchell RS, Miller DC, Stinson EB, et al. Significant patient-related determinants of prosthetic valve performance. J Thorac Cardiovasc Surg 1986;91:807-17.

17 Starr A. The Starr-Edwards valve. J Am Coll Cardiol 1985;6:899-903.

18 Fuster V, Gersh BJ, Giuliani ER, Tajik AJ, Brandenburg RO, Frye RL. The natural history of idiopathic dilated cardiomyopathy. $\mathrm{Am} J$ Cardiol $1981 ; 47: 525-31$.

19 Holley KE, Bahn RC, McGoon DC, Mankin HT. Spontaneous calcific embolisation associated with calcific aortic stenosis. Circulation 1963;27:197-200.

20 Rutledge R, Kim BJ, Applebaum RE. Actuarial analysis of the risk of prosthetic valve endocarditis in 1598 patients with mechanical and bioprosthetic valves. Arch Surg 1985;120:469-72.

21 Sweeney MS, Reul GJ, Cooley DA, et al. Comparison of bioprosthetic and mechanical valve replacement for active endocarditis. J Thorac Cardiovasc Surg 1985;90:676-80.

22 Perier P, Bessou JP, Swanson JS, et al. Comparative evaluation of aortic valve replacement with Starr, Björk, and porcine valve prostheses. Circulation 1985;72(suppl II):140-5.

23 McGilligan DJ, Lewis JW, Heinzerling RH, Smith D. Fate of a second porcine bioprosthesis valve. $J$ Thorac Cardiovasc Surg 1983;85:362-70. 